\title{
summary
}

\section{Dental appliances may be useful for the treatment of obstructive sleep apnoea}

Wilhelmsson B, Tegelberg A, Walker-Engstron M-L, Ringqvuist M, Andersson L, Krekmanov, et al. A prospective randomised study of a dental appliance compared with uvulopalatopharyngoplasty in treatment of obstructive sleep apnoea. Acta Otolaryngol 1999; 119:503-509

Question: In patients with obstructive sleep apnoea are dental appliances as effective as uvulopalatopharyngoplasty?

Objective To compare the effect of dental appliance and uvulopalatopharyngoplasty (UPPP) for treatment of obstructive sleep apnoea.

Design Randomised controlled trial.

Intervention UPPP or a dental appliance to achieve mandibular advancement of $50 \%$ of maximum protrusive capacity.

Outcome measures Apnoea index (AI), apnoea/ hypoxia index (AHI), oxygen desaturation index (ODI) and snoring index (SI).

Results Both groups showed significant decrease in the values for AI, AHI, ODI and SI at 6 and 12 months. At 12 months AI and AHI were significantly better in the dental-appliance group but other outcomes showed no difference (see Table 1).

Conclusions Evidence suggests that dental appliances may be a useful adjunct to the treatment of obstructive sleep apnoea.
Table 1 Outcomes from use of dental appliance or UPPP in obstructive sleep apnoea

\begin{tabular}{|c|c|c|c|c|}
\hline & \multicolumn{2}{|c|}{$\begin{array}{l}\text { Dental appliance } \\
\text { Mean }(95 \% \mathrm{Cl})\end{array}$} & \multicolumn{2}{|c|}{$\begin{array}{c}\text { UPPP } \\
\text { Mean }(95 \% \mathrm{Cl})\end{array}$} \\
\hline & Baseline & 12 months & Baseline & 12 months \\
\hline Al & $10.8(9.2-12.4)$ & $2.4(0.7-4.0)$ & $12.3(10.7-13.9)$ & $5.5(3.6-7.4)$ \\
\hline $\mathrm{AHI}$ & $18.2(15.7-20.8)$ & $6.0(3.0-8.9)$ & $20.4(17.4-23.3)$ & $10.4(7.6-13.2)^{*}$ \\
\hline ODI & $17.0(14.1-19.8)$ & $6.1(2.9-9.4)$ & $18.4(15.0-21.8)$ & $9.3(6.3-12.3)$ \\
\hline SI & $0.7(0.6-0.8)$ & $0.5(0.4-0.6)$ & $0.7(0.7-0.8)$ & $0.5(0.5-0.6)$ \\
\hline
\end{tabular}

*Significant at $P=0.05$.

Evidence-Based Dentistry (2002) 3, 51. doi:10.1038/sj. ebd.6400103

Address for reprints: Bo Wilhelmsson, Department of

Otorhinolaryngology, Central Hospital, SE-721 Vasteras, Sweden.

Fax: +46 21175364.

\section{Commentary}

The methodology used in this study is refreshing because UPPP results are usually reported as being successful when AHI is reduced by $50 \%$. This is only meaningful in mild cases, as the authors reported in the article. 'Curative' value would be an AHI $<10$, AI $<5$ or AHI 510 without excessive daytime somnolence. These are definitions of the disease and treatment such that it is eliminated.

The reported cases are all relatively mild. Commonly in clinical practice patients are treated when there is an AHI $>40$. Since there is evidence ${ }^{1}$ that an AI of at least 20 is associated with significant mortality, halving a rate of 45 would not improve life expectancy.

Importantly, this article demonstrates the futility in trying to determine a site of obstruction, at least using fibreoptic pharyngoscopy with the Müller Manoevre (FPMMM). Presumably the mandibular advancement dental appliance described would have its effect at the level of the hypopharynx, yet most of the group treated this way demonstrated a Fujita type I (oropharyngeal) obstruction. Clinically, attempts to determine the site of obstruction (eg, 3-D CAT or ultra-fast MRI) may be more costly and less effective than a trial using an adjustable mandibular adjustment device (MAD) and a polysomnogram.

Many nonadjustable MADs have been used effectively. ${ }^{2,3}$ In recent years, however, clinicians have also used MADs with an adjustable amount of protrusion. The " $50 \%$ of maximum protrusion" used in the study device may be ideal for some patients but not for others. Other clinical techniques may give a more ideal fixed position ${ }^{4}$, but with many clinicians now using adjustable MADs, the devices are titrated to an effective protrusion for the individual patient. $^{5}$
1. He J, Kryger MH, Zorick FJ. Mortality and apnea index in obstructive sleep apnea experience in 385 male patients. Chest 1988; 94:9-14.

2. Cohen RB. Obstructive sleep apnea; oral appliance therapy and severity of condition. Oral Surg Oral Med Oral Pathol 1998; 85:388-392.

3. George PT. Selecting sleep-disorderedbreathing appliances: biomechanical considerations. JADA 2001; 132:339-347.

4. Cohen RB. Obstructive sleep apnea: mandibular treatment device for the treatment and diagnosis of obstruction site. Comp Cont Ed Dent 1995; 16:622-628.

5. Ivanhoe JR, Cibirka RM, Lefebvre CA, Parr GR. Dental considerations in upper airway sleep disorders: a review of the literature. J Pros Dent 1999; 82:685-698.

Robert Cohen Tufts University School of Dental Medicine, Boston, Massachusetts, USA 